\title{
Increased intensity of interference fringes in Digital Holography
}

\section{Aumento de la intensidad de franjas de interferencia en Holografía Digital}

\author{
LÓPEZ-ÁLVAREZ, Yadira Fabiola ${ }^{1,2} \dagger^{*}$, PEÑA-LECONA, Francisco Gerardo ${ }^{2}$, JARA-RUIZ, Ricardo $^{1}$ \\ and HERRERA-SERRANO, Jorge Eduardo ${ }^{1}$
}

${ }^{1}$ Universidad Tecnológica del Norte de Aguascalientes, Estación Rincón, Rincón de Romos, Aguascalientes, 20400 México. ${ }^{2}$ Departamento de Ciencias Exactas y Tecnología, Centro Universitario de los Lagos, CULagos. Universidad de Guadalajara, Lagos de Moreno, Jalisco, 47460, México

ID $1^{\text {st }}$ Author: Yadira Fabiola, López-Álvarez, ORC ID: 0000-0002-9041-1908, Researcher ID Thomson: T-1555-2018, CVU CONACYT ID: 375952

ID $1^{\text {st }}$ Coauthor: Francisco Gerardo, Peña-Lecona / ORC ID: 0000-0002-9537-8633, CVU CONACYT ID: 122563

ID $2^{\text {nd }}$ Coauthor: Ricardo, Jara-Ruiz / ORC ID: 0000-0001-7725-4138, Researcher ID Thomson: T-1532-2018, CVU CONACYT ID: 630276

ID $3^{\text {rd }}$ Coauthor: Jorge Eduardo, Herrera-Serrano / ORC ID: 0000-0002-3960-8406, CVU CONACYT ID: 881987

DOI: $10.35429 /$ JTD.2019.12.3.1.6

Received June 26, 2020; Accepted November 28, 2020

\begin{abstract}
Digital holographic interferometry is a full field optical technique, used in the measurement of dynamic and non-contact events, this technique works with arrays where the initial acquisition of interference fringes is not necessary, but rather involves the superposition of two wave fronts. Where from the holograms and by means of a Fourier window-based processing it is feasible to recover the information of both intensity and phase. However, the interference fringes resulting from the demodulation of the holograms may have low intensity, affecting their subsequent analysis. In this work, the combination of the holographic techniques, filters and the superposition principle is proposed to increase the intensity of the fringes, the results show that using the Fourier method in combination with the superposition theorem is possible to obtain greater intensity between the minimum and maximum of the fringes.
\end{abstract}

Digital holographic interferometry, Fourier, Filters

\begin{abstract}
Resumen
La interferometría holográfica digital es una técnica óptica de campo completo, utilizada en la medición de eventos dinámicos y de no contacto, esta técnica trabaja con arreglos donde no es necesario la adquisición inicial de franjas de interferencia, si no que implica la superposición de dos frentes de onda, donde a partir de los hologramas y mediante un procesamiento a base de ventanas de Fourier es factible recuperar la información tanto de intensidad como de la fase. Sin embargo, las franjas de interferencia resultantes de la demodulación de los hologramas pueden tener poca intensidad viéndose afectado su posterior análisis. En este trabajo se propone la combinación de técnicas holográficas, filtros y el principio de superposición para aumentar la intensidad de las franjas, los resultados muestran que utilizado el método de Fourier cotidiano en combinación con el teorema de superposición es posible obtener mayor intensidad entre los mínimos y máximos de las franjas.
\end{abstract}

Interferometría holográfica digital, Fourier, Filtro

Citation: LÓPEZ-ÁLVAREZ, Yadira Fabiola, PEÑA-LECONA, Francisco Gerardo, JARA-RUIZ, Ricardo and HERRERASERRANO, Jorge Eduardo. Increased intensity of interference fringes in Digital Holography. Journal of Technological Development. 2020. 4-14: 1-6

\footnotetext{
* Correspondence to Author (email: beatrizeugenia_m_mtz@yahoo.com.mx)

$\dagger$ Researcher contributing first author.
} 


\section{Introduction}

The development of systems for the measurement of physical variables has applications in different industrial areas such as automotive, naval, aerospace, biochemistry, and even medicine (Huggins, 1992), (Aguado, 2017), (X.J., 2003).Technological advances require that these devices present design and operation advantages over every day industrial instrumentation (Giallorenzi, 1982), so the incorporation of devices with micro-scale technology would meet the size and accessibility requirements, however, these imply a complicated construction and design process (Chikovani, 2017).

The use of optical metrology for the monitoring of different variables has had a great boom in recent decades, among the optical techniques highlighting the phase recovery of two wave fronts through cross-correlation techniques (Percival, 2009), (Yamaguchi, 1989 ), diffraction and polarization (Marciel, 1995). The first devices that make use of fiber optics as a transducer system are based on the Sagnac effect (Kurzych, 2016), Fabry-Perot and MachZehnder (Lutang, 2017), among other configurations, however, their construction requires great stability in the system.

Digital holographic interferometry (DHI), is a non-destructive, full-field optical technique that is used in the measurement of dynamic and static events, it is based on the superposition of two wave fronts, but unlike an interferometer it requires a correlation of two holograms to determine the phase.

In addition to the accessibility of the technique, another advantage that digital holography presents over interferometry is that it can work on rough surfaces, its design is relatively simple and applicable to longitudinal measurements (Saito, 1971). However, in the process of demodulation of holograms, the information contained in them can be affected by noise originated by the same measuring instruments, lenses, mirrors and sensor of the CCD camera (Charge Coupled Device). In this work, a technique to increase the intensity of the interference fringes caused by the correlation of two holograms is presented by superimposing the same signals.
In section 2 , the optical system to obtain holograms, in section 3 , the numerical principles, the phase estimation, the relationship between a phase difference between two holograms, the interference fringes and the superposition method are shown for greater intensity. In section 4, an experimental example is developed, and the results are shown, and finally in section 5 the conclusions of the work.

\section{Experimental setup}

Figure 1 shows the standard optical system, used to obtain holograms in the measurement of different variables, it is applied to measure concentration of liquid substances, temperature changes, among many others.

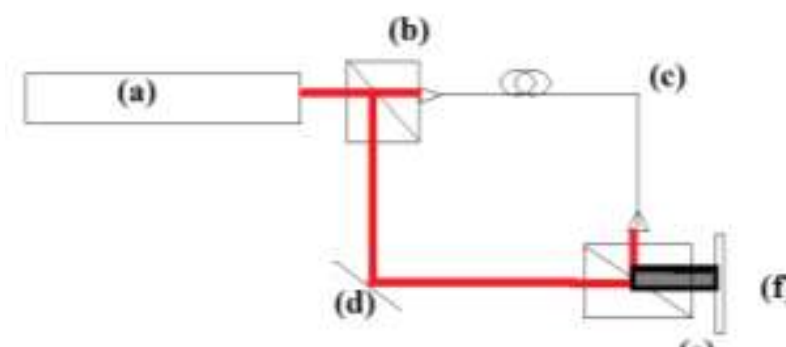

(e)

Figure 1 Diagram of the optical system used in DHI, (a) He-Ne 633nm laser, (b) Beam splitter cube 1, (c) Optical fiber, (d) Mirror, (e) Beam splitter cube 2 and (f) CCD camera

Source: Own Elaboration

\section{Methods and development}

Digital Holographic Interferometry is a widely studied non-contact optical technique that works with arrangements where the initial acquisition of interference fringes is not necessary, it only involves the superposition of two wave fronts, where from the holograms obtained and by means of in a Fourier window-based processing, it is feasible to recover the information of both the intensity and the phase of the wave fronts from the same source (Kreis, 2005). The intensity detected by the CCD sensor of each image is $\mathrm{I}_{\mathrm{H}}(\mathrm{x}, \mathrm{y})$, according to equation (1).

$$
\begin{aligned}
& I_{H}(x, y)=\left|U_{R}(x, y)\right|^{2}+\left|U_{0}(x, y)\right|^{2}+ \\
& U_{R}^{*}(x, y) U_{0}(x, y)+U_{R}(x, y) U_{0}^{*}(x, y) \\
& U_{R}(x, y)=u_{r}(x, y) \exp ^{i \varphi(x, y)} \\
& U_{0}(x, y)=u_{0}(x, y) \exp ^{-i 2 \pi\left(\varphi_{x} x+\varphi_{y} y\right)}= \\
& u_{0}(x, y) \exp ^{-i \varphi_{1}(x, y)}
\end{aligned}
$$


$\mathrm{U}_{\mathrm{R}}(\mathrm{x}, \mathrm{y})$ and $\mathrm{U}_{0}(\mathrm{x}, \mathrm{y})$ are the reference beam and the one passing through the object, $(x, y)$ denote the coordinates in the plane of the hologram, $\left(\varphi_{\mathrm{x}} \mathrm{x}, \varphi_{\mathrm{y}} \mathrm{y}\right)$ describe the spatial frequencies and $*$ denotes the complex conjugate,

Which results in:

$$
\begin{aligned}
& I_{H}(x, y)=a(x, y)+c(x, y) e^{i 2 \pi\left(\varphi_{x} x,+\varphi_{y} y\right)}+ \\
& c^{*}(x, y) e^{-i 2 \pi\left(\varphi_{x} x+\varphi_{y} y\right)}
\end{aligned}
$$

Where:

$$
\begin{aligned}
& (x, y)=u_{r}(x, y)^{2}+u_{0}(x, y)^{2} \quad y \\
& c(x, y)=u_{r}(x, y)+u_{0}(x, y) \exp ^{i \varphi(x, y)}
\end{aligned}
$$

Applying the Fourier Transform:

$F\left\{I_{H}(x, y)\right\}=\mathrm{I}(\mathrm{u}, \mathrm{v})=\mathrm{A}(\mathrm{u}, \mathrm{v})+\mathrm{C}\left(\mathrm{u}-\mathrm{f}_{\mathrm{x}}, \mathrm{v}-\right.$ $\left.\mathrm{f}_{\mathrm{y}}\right)+\mathrm{C}^{*}\left(\mathrm{u}+\mathrm{f}_{\mathrm{x}}, \mathrm{v}-\mathrm{f}_{\mathrm{y}}\right)$

A band-based filter is applied separating one of the last two terms of equation (5), finally obtaining the phase distribution.

$$
\varphi(\mathrm{x}, \mathrm{y})+2 \pi\left(\mathrm{f}_{\mathrm{x}} \mathrm{x}+\mathrm{f}_{\mathrm{y}} \mathrm{y}\right)=\arctan \frac{\operatorname{Im}\left[\mathrm{C}\left(\mathrm{u}-\mathrm{f}_{\mathrm{x}}, \mathrm{v}-\mathrm{f}_{\mathrm{y}}\right)\right]}{\operatorname{Re}\left[\mathrm{C}\left(\mathrm{u}-\mathrm{f}_{\mathrm{x}}, \mathrm{v}-\mathrm{f}_{\mathrm{y}}\right)\right]}
$$

\subsection{Determination of phase with DHI.}

To determine the phase changes, it is necessary to capture a second hologram determined by:

$$
\begin{aligned}
& \mathrm{I}_{\mathrm{H}}^{\prime}(\mathrm{x}, \mathrm{y})=\left|\mathrm{U}_{\mathrm{R}}(\mathrm{x}, \mathrm{y})\right|^{2}+\left|\mathrm{U}_{\mathrm{O}}^{\prime}(\mathrm{x}, \mathrm{y})\right|^{2}+ \\
& \mathrm{U}_{\mathrm{R}}^{*}(\mathrm{x}, \mathrm{y}) \mathrm{U}_{\mathrm{O}}^{\prime}(\mathrm{x}, \mathrm{y})+\mathrm{U}_{\mathrm{R}}(\mathrm{x}, \mathrm{y}) \mathrm{U}_{\mathrm{O}}^{\prime *}(\mathrm{x}, \mathrm{y})
\end{aligned}
$$
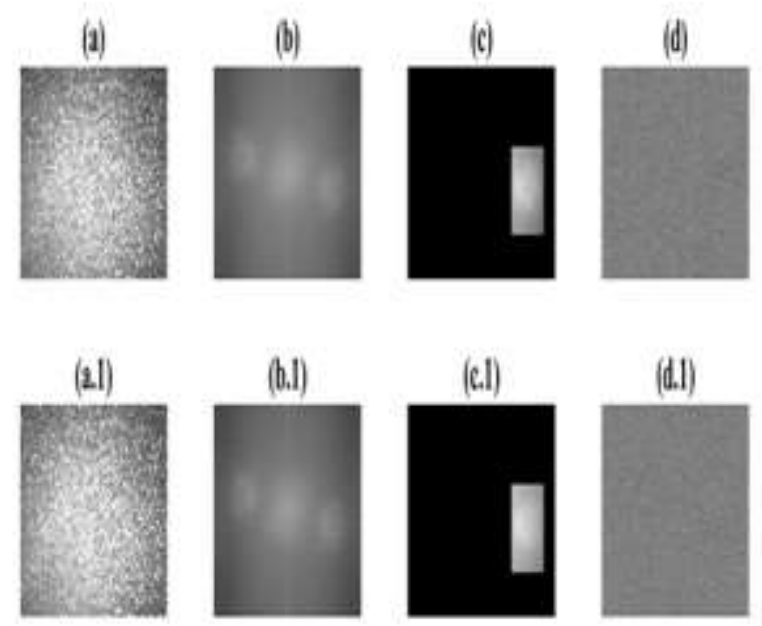

Figure 2 Interference phase recovery process using DHI, Source: Own Elaboration
The Figure 2 describes the process of recovery of the phase of two holograms with different states, the deformation was induced in the fiber optic arm shown in Figure 1, (a) $\mathrm{I}_{\mathrm{H}}(\mathrm{x}, \mathrm{y})$,(a.1) $\mathrm{I}_{\mathrm{H}}^{\prime}(\mathrm{x}, \mathrm{y})$, (b) $\mathrm{F}\left\{\mathrm{I}_{\mathrm{H}}(\mathrm{x}, \mathrm{y})\right\}$, (b.1) $\mathrm{F}\left\{\mathrm{I}_{\mathrm{H}}^{\prime}(\mathrm{x}, \mathrm{y})\right\}$, (c) $\mathrm{C}\left(\mathrm{u}-\mathrm{f}_{\mathrm{x}}, \mathrm{v}-\mathrm{f}_{\mathrm{y}}\right)$, (c.1) $\mathrm{C}^{\prime}\left(\mathrm{u}-\mathrm{f}_{\mathrm{x}}, \mathrm{v}-\mathrm{f}_{\mathrm{y}}\right)$, (d) $\varphi(\mathrm{x}, \mathrm{y})+2 \pi\left(\mathrm{f}_{\mathrm{x}} \mathrm{x}+\right.$ $\left.\mathrm{f}_{\mathrm{y}} \mathrm{y}\right)$ y $(\mathrm{d} .1) \varphi_{1}^{\prime}(\mathrm{x}, \mathrm{y})+2 \pi\left(\mathrm{f}_{\mathrm{x}} \mathrm{x}+\mathrm{f}_{\mathrm{y}} \mathrm{y}\right)$, to obtain a phase difference between the two states, the reference state and the one that undergoes an optical path change, it is considered that the reference remains constant in the experiment, $U_{R}(x, y)=u_{r}(x, y) \exp ^{i \varphi(x, y)}$, while the beam passing through the optical fiber will exhibit a phase shift, $\mathrm{U}_{\mathrm{O}}^{\prime}(\mathrm{x}, \mathrm{y})=\mathrm{u}_{0}^{\prime}(\mathrm{x}, \mathrm{y}) \exp ^{\mathrm{i} \varphi_{1}^{\prime}(\mathrm{x}, \mathrm{y})}$.

\section{Diferencia de fase entre dos hologramas}

The pattern of interference fringes that is characteristic between two states can be calculated as a subtraction of two phases.

$\Delta \phi_{\mathrm{m}}=\varphi_{1}^{\prime}(\mathrm{x}, \mathrm{y})-\varphi(\mathrm{x}, \mathrm{y})$

For the study of dynamic events using DHI, the process involves determining the phase changes at each point of the induced deformation, $\varphi_{\mathrm{j}}^{\prime}(\mathrm{x}, \mathrm{y})$.
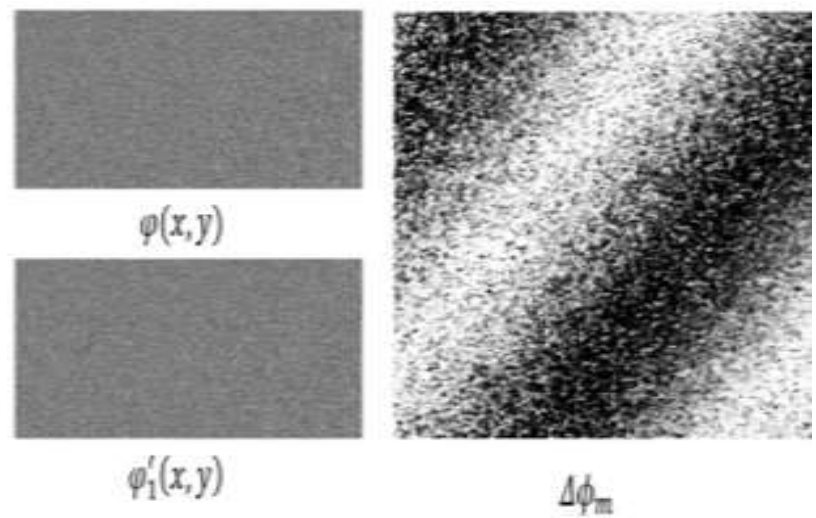

Figure 3 Phase difference between $\mathrm{I}_{\mathrm{H}}(\mathrm{x}, \mathrm{y})$ and $\mathrm{I}_{\mathrm{H}}^{\prime}(\mathrm{x}, \mathrm{y})$ Source: Own Elaboration

\section{Method of enhancing fringes by superposition}

In the region where the waves are superimposed, the intensity varies between one point and another of each of the signals, obtaining minimums and maximums, giving rise to constructive or destructive interferences and given that the principle of superposition suggests in general that when two or more waves coincide in time and space, the resulting in a function is the vector sum of the individual wave functions (Buerbano, 2003). 
From the wave superposition theorem at a point and considering that the resulting equation must also comply with the wave equation, an approximation can be made in the behavior of the interference fringes with this principle.

Given the:

$$
\begin{aligned}
& \varphi_{1}(\mathrm{x}, \mathrm{t})=\mathrm{f}_{1}(\mathrm{x}+\mathrm{ct}) \\
& \varphi_{2}(\mathrm{x}, \mathrm{t})=\mathrm{f}_{2}(\mathrm{x}-\mathrm{ct}) \\
& \varphi_{\mathrm{T}}(\mathrm{x}, \mathrm{t})=\varphi_{1}(\mathrm{x}, \mathrm{t})+\varphi_{2}(\mathrm{x}, \mathrm{t})
\end{aligned}
$$
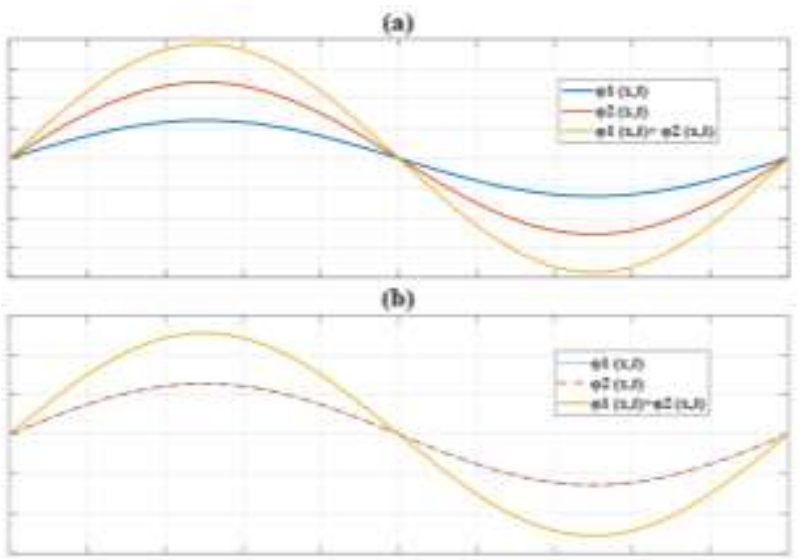

Figure 4 Principle of superposition of two functions, (a) with different amplitude $\varphi_{1}(\mathrm{x}, \mathrm{t}) \neq \varphi_{2}(\mathrm{x}, \mathrm{t})$, (b) with equal amplitude $\varphi_{1}(\mathrm{x}, \mathrm{t})=\varphi_{2}(\mathrm{x}, \mathrm{t})$

Source: Own Elaboration

Figure 4 shows two examples of the behavior of the superposition principle used in this work, in (a) the increase in the amplitude of the signal is shown with the algebraic sum of two signals with different amplitude, while in (b) the F1 and F2 signals have the same amplitude.

\section{Fringes pattern demodulation}

To determine the phase distribution, PSI phase shift interferometry is a phase map unfolding technique, where it records a series of interferograms with phase differences, as shown by equation (12). To carry out the phase reconstruction process, in general, algorithms with a combination of interferograms are applied; the analysis can be done with $\mathrm{n}=$ 1,2,.. M interferograms (Schwider, 1983).

$\tan \varphi=\frac{\sum_{\mathrm{n}=1}^{\mathrm{M}} \mathrm{b}_{\mathrm{n}} \mathrm{I}_{\mathrm{n}}}{\sum_{\mathrm{n}=1}^{\mathrm{M}} \mathrm{a}_{\mathrm{n}} \mathrm{I}_{\mathrm{n}}}$

With $a_{n}$ and $b_{n}$, as real coefficients.

\section{Results}

For the analysis of the fringes resulting from the phase difference between each hologram, its profile is considered, see Figure 5.

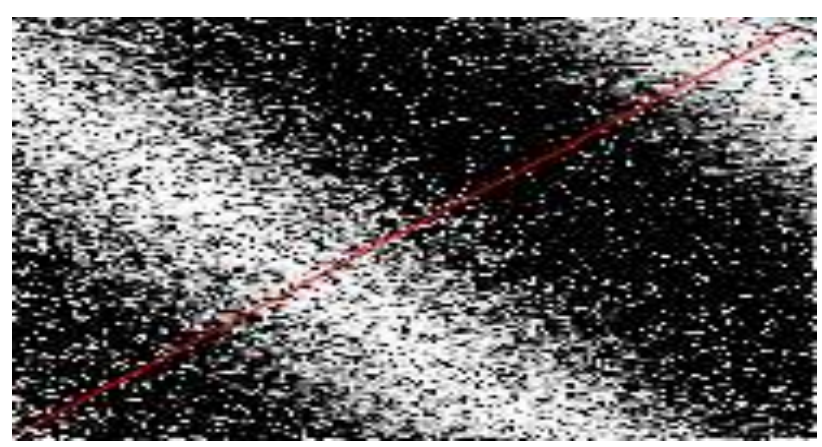

Figure 5 Interference fringes originating from the phase difference of two holograms

Source: Own Elaboration

Figure 6 shows the maximums and minimums of the interference signal, a polynomial approximation is carried out to eliminate noise in the signal. The approximation is used to implement the superposition theorem and show that the amplitude in the intensity of the fringes also increases.

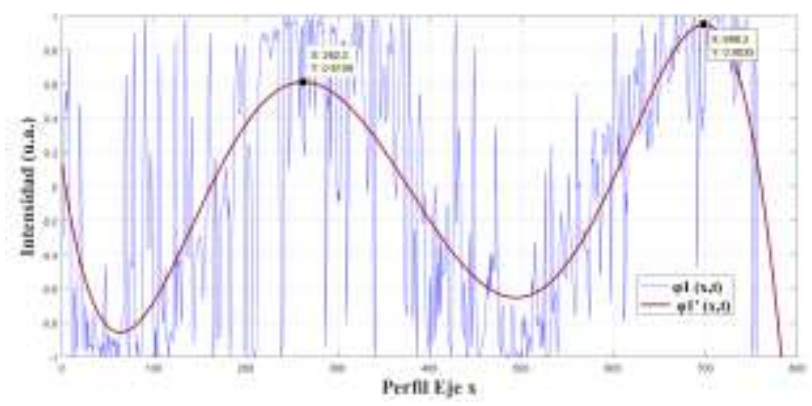

Figure 6 Profile of interference fringes originating from the phase difference of two holograms, with polynomial approximation

Source: Own Elaboration

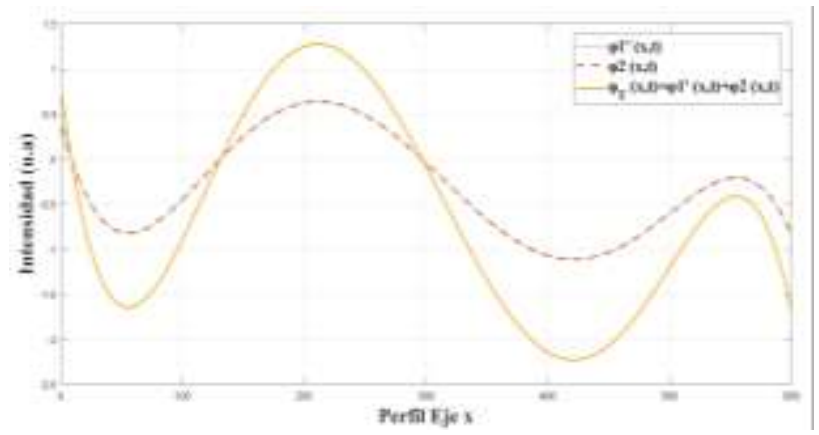

Figure 7 Profile of interference fringes originating from the phase difference of two holograms, with polynomial approximation

Source: Own Elaboration 
Figure 7 shows the profile of the interference fringes that were used to increase the intensity in the interference fringes when $\varphi_{1}(\mathrm{x}, \mathrm{t})=\varphi_{2}(\mathrm{x}, \mathrm{t})$.

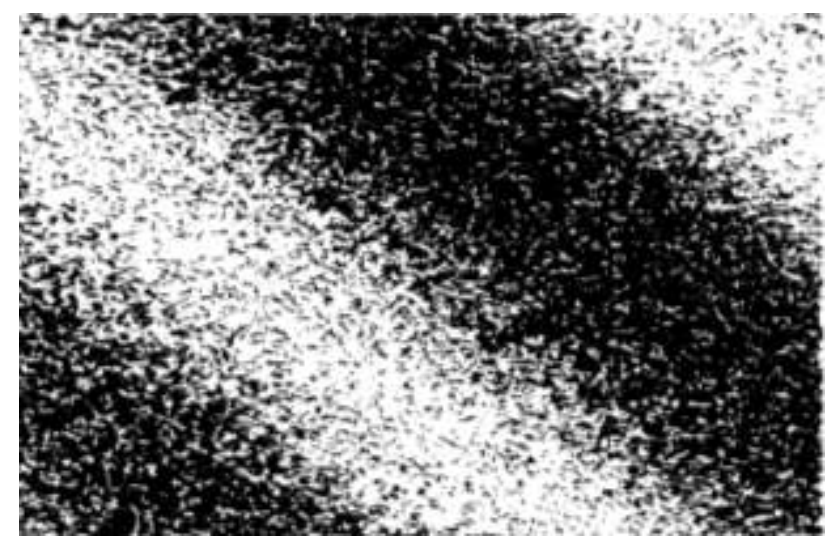

Figure 8 Interference fringes originating from the phase difference of two holograms with twice their intensity Source: Own Elaboration

Equation (12) is used to determine the characteristic phase map of the interference fringes. In Figure 9 the phase maps for the original interference patterns are shown and when their intensity is increased, the properties are still preserved, which suggests that it is feasible to increase the sharpness of the interference patterns without altering their behavior.

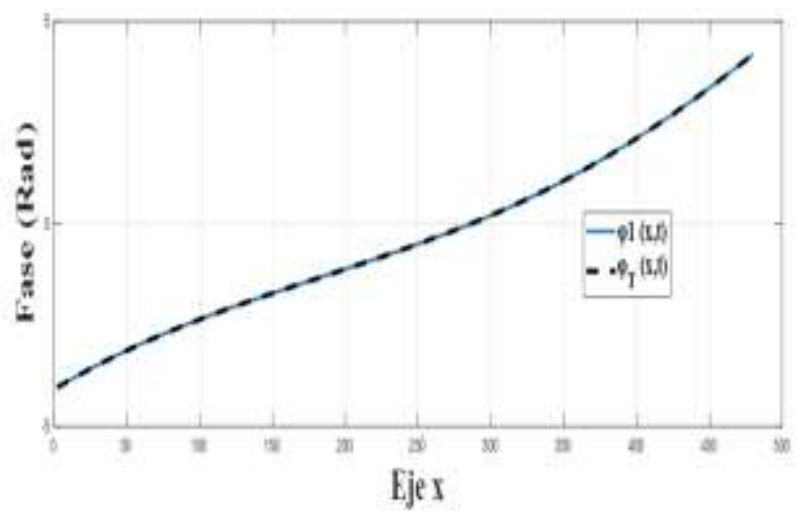

Figure 9 Phase maps of the interference fringes Source: Own Elaboration

\section{Conclusion}

A simple method is presented for increasing the intensity of interference fringes obtained Holographic Interferometry by Digital, the process shows the geometric distribution of the interference fringes is not lost and it continues to retain its same phase map. The proposed intensity increase method is implemented in the difference of holograms with high frequency, where the quality of the fringes is affected, both by the instruments and by the characteristics of the same technique.

\section{References}

Aguado Rojas Missie, Pasillas Lépine William, Loría Antonio, De Bernardinis Alexandre. (2017). Angular velocity estimation from incremental encoder measurements incremental encoder measurements in the presence of sensor imperfections. IFAC-PapersOnLine.50(1) 59795984.

Buerbano Santiago. (2003). Física general, Tébar, SL.

Chikovani, V. V., \& Tsiruk, H. V. (2017). Digital rate MEMS vibratory gyroscope modeling, tuning and simulation results. Computación y Sistemas, 21(1), 147-159.

Giallorenzi, T. G., Bucaro, J. A., Dandridge, A., Sigel, G. H., Cole, J. H., Rashleigh, S. C., \& Priest, R. G. (1982). Optical Fiber Sensor Technology. IEEE Journal of Quantum Electronics, 18(4), 626-665.

Huggins, R. W., Abbas, G. L., Hong, C. S., Miller, G. E., Porter, C. R., \& Van Deventer, B. (1992). Fiber-coupled position sensors for aerospace applications. Optics and Lasers in Engineering, 16(2-3), 79-103.

Kreis, T. (2005). Handbook of holographic interferometry: Optical and Digital Methods. Klagenfurter: WILEY-VCH Verlag GmbH \& Co.KGaA.

Kurzych, A., Kowalski, J. K., Sakowicz, B., Krajewski, Z., \& Jaroszewicz, L. R. (2016). The laboratory investigation of the innovative sensor for torsional effects in engineering structures' monitoring. Opto-Electronics Review.

Lutang Wang and Nian Fang. (2017). Applications of Fiber-Optic Interferometry Technology in Sensor Fields, InTechOpen.

Mancier Nathalie, Chakari Ayoub, Meyrueis Patrick, and Clément Michel. (1995). Angular displacement fiber-optic sensor: theoretical and experimental study. Appl. Opt., 34(28).

Percival F. Almoro, Giancarlo Pedrini, Arun Anand, Wolfgang Osten, and Steen G. Hanson. (2009). Angular displacement and deformation analyses using a speckle-based wavefront sensor. Appl. Opt. 48(5). 
Saito, H., Yamaguchi, I., \& Nakajima, T. (1971). Application of Holographic Interferometry to Mechanical Experiments. In Applications of Holography. Springer US, 105-126.

Schwider J., Burow R., Elssner K.-E., Grzanna J., Spolaczyk R., and Merkel K. (1983)."Digital wave-front measuring interferometry: some systematic error sources," Appl. Opt. 22, 34213432.

X.J. Zhang, S. Rappel, R.W. Bernstein, C.-C. Chenl, 0. Sahin, M. Scott and 0. Solgaard. (October,2003). High-precision characterization of embryo positioning force using mems optical encoder. 7th international Conference on Miniaturized Chemical and Biochemical Analysts Systems, Squaw Valley, California USA.

Yamaguchi, I. (1989). Encoder and strain gauge using laser speckle. Optics and Lasers in Engineering. 11(4), 223-232. 